\title{
Perceived Benefits of Complementary and Alternative Medicine: A Whole Systems Research Perspective
}

\author{
Angela M. Greene ${ }^{1, *}$, Edith G. Walsh ${ }^{2}$, Fuschia M. Sirois ${ }^{3}$ and Anne McCaffrey ${ }^{4}$
}

${ }^{I}$ RTI International, Research Triangle Park, NC, USA; ${ }^{2}$ RTI International, Waltham, MA, USA; ${ }^{3}$ Department of Psychology, University of Windsor, Windsor, ON, Canada $;{ }^{4}$ Marino Center for Progressive Health, Boston, MA, USA; and Division for Research and Education in Complementary and Integrative Medical Therapies, Harvard Medical School Osher Institute, Boston, MA, USA

\begin{abstract}
The purpose of this study was to examine the benefits associated with complementary and alternative medicine (CAM) treatments from the patients' perspective using a whole systems research approach as a guiding framework.

We conducted five focus groups of six to eight participants each, with users of CAM recruited through experienced CAM providers and clinics. Eligible participants were aged 21 or older, had used CAM in the last 12 months, and believed the treatment to be beneficial. The focus group discussions were digitally recorded, transcribed, and analyzed through a qualitative content analysis. Responses were inductively coded for common themes, and then placed into broader conceptual categories reflecting the CAM outcome domains suggested by Verhoef and colleagues. Participants described physical health benefits including symptom relief and improved function, and positive psychological benefits such as improved coping and resilience. Social health benefits that arose from the positive aspects of the patient-practitioner relationship were also reported, including support and advocacy. In addition, participants identified empowerment, increased hope and spiritual growth as results of receiving CAM treatments. A new behavioral health outcome domain emerged as participants reported that CAM use had fostered behavioral changes such as increased exercise, smoking cessation and improving their diets.

These patient-reported benefits of CAM treatment are consistent with the outcome model proposed by Verhoef and colleagues, and extend this model by identifying a new outcome domain—behavioral health outcome. The findings provide insight and direction for the development of outcome and process measures to evaluate CAM treatment effects.
\end{abstract}

\section{INTRODUCTION}

As interest in and use of complementary and alternative medicine continues to rise, so does the need to identify and understand the full range of treatment effects. Indeed, it has been noted that evaluating the effectiveness of CAM necessarily relies on the choice and range of outcomes evaluated [1]. Moreover, conceptual clarification of the factors that give rise to these effects is considered essential to ensure that the outcomes being evaluated are those that matter most to CAM users [2]. To this end, researchers have suggested taking a whole systems research perspective to view the multiplicity of CAM outcomes and their potentially synergistic interactions with contextual and personal factors [3-5]. This framework includes a consideration of specific or symptomfocused effects, as well as other non-specific effects that fall within the boundaries of psychological, social, and spiritual benefits [4]. Although comprehensive, it is unknown if these outcome domains reflect the full range of experiences of CAM users because the categories were derived from survey responses by CAM researchers and practitioners. The purpose of the current study was, therefore, to explore the domains of benefits and outcomes associated with CAM

*Address correspondence to this author at RTI International, 3040 Cornwallis Rd., P.O. Box 12194, Research Triangle Park, NC 27709-2194, USA; Tel: 919-541-6675; Fax: 919-990-8454; E-mail: amg@rti.org treatments from the patients' perspective using a whole systems research approach as a guiding framework.

\section{Conceptualizing CAM Outcomes}

A focus on evidence-based practice in recent years has prompted discussion about how CAM outcomes should be conceptualized and evaluated. Although the importance of including an assessment of the patient's subjective experience of CAM therapies to identify key outcome criteria has emerged from this discussion, there remains some debate regarding the range of effects that should be considered [2, 4]. Moreover, the diversity of CAM outcomes that can be considered treatment "effects" has led researchers to suggest that a holistic perspective is necessary to fully understand, distinguish, and measure the benefits of CAM interventions $[1,4]$.

Long [2] suggests that understanding the source of CAM effects is key to both identifying what constitutes an effect and to distinguishing certain outcomes from each other. He suggests that there are three basic types of effects: effects that arise from the philosophy of health and healing, effects that arise from the patient-practitioner relationship, and effects that are brought about by specific techniques used by the CAM practitioner to enhance the healing process [2]. The first type of effect is intertwined with the meaning of health as it relates to CAM, including such concepts as self-care, 
holistic health beliefs, and a systems or biopsychosocial approach to healing and health. The second type of effect is most often described as "non-specific" and involves concepts such as hope, trust, empathy, and encouragement that may hasten healing processes by supporting the patients' belief that healing is possible. Finally, the third type of effect involves the tools and techniques that are unique to individual CAM modalities, including acupuncture needling techniques, specific homeopathic remedies, and body manipulation techniques. Long [2] suggests that such distinctions are necessary to not only identify CAM treatment effects but also to evaluate the "full" effects, which include outcomes related to each of these sources.

\section{A Whole Systems Approach to CAM Outcomes}

Moving from a focus on the source of CAM outcomes, other researchers have developed a preliminary framework for categorizing the nature of CAM effects that highlights their interaction. Based on a whole systems research approach [3, 6], Verhoef and colleagues [4] propose four CAM outcome domains that give rise to a sense of holistic wellness. Physical outcomes relate to dimensions of physical well-being and include biological markers, physical functioning, and symptoms such as pain and fatigue. Psychological outcomes include those related to mental and emotional well-being, including mood, motivation, and perceptions related to health and healing such as control, resilience, and expectations. Social support, relationship factors, health-care utilization, and daily role functioning are examples of social outcomes related to CAM treatments. Finally, benefits such as empowerment, hope, and relaxation are conceptualized as spiritual outcomes associated with CAM.

Rather than being discrete domains, these outcomes are viewed as interacting synergistically with each other and with the contextual and personal factors that are integral to the process of healing. Consistent with Long's [2] model, the whole systems model presents aspects of the patient-provider relationship as key factors that can affect treatment outcomes. Moreover, it includes a holistic outcomes category that encompasses the four main outcome categories and assesses this often overlooked outcome of CAM care [1]. Because a whole systems approach includes both the specific and non-specific effects of CAM treatment, it provides a potentially valuable framework for understanding and optimizing the full effects of CAM treatments.

\section{The Present Study}

Despite the apparent utility of the whole systems model, it is still unclear whether the model reflects the full range of outcomes that CAM patients perceived as benefits from treatment. The domains were derived from the survey responses of practitioners and researchers regarding their observations of CAM outcomes. It has, however, been suggested that the best way to capture the range of ways in which CAM benefits its users is through experience-based evidence obtained directly from those users [2].

One way of obtaining this type of evidence is by using focus groups. Indeed, several studies have employed focus groups as a means to better understand the motivations for using CAM [7-12], but there are relatively few studies that have examined the perceived benefits of CAM from the pa- tient's perspective. Among those that have, the focus was on outcomes regarding a single CAM therapy $[13,14]$, a limited set of CAM outcomes [15], or satisfaction with CAM care [16]. Thus, there is a need to explore the full range of benefits perceived by CAM patients and, further, to examine if these perceived benefits are captured by the domains suggested by current models of CAM outcomes.

The purpose of this study was, therefore, to address this gap by using a focus group methodology to examine the benefits associated with CAM treatments from the patients' perspective using a whole systems research approach as a guiding framework. Because focus groups provide a dynamic forum from which new and unexpected themes may emerge from the natural flow of conversation [17], we felt that this methodology would be particularly relevant for examining and possibly expanding the outcomes from a whole systems research perspective.

\section{MATERIALS AND METHODOLOGY}

To identify benefits and outcomes experienced by CAM consumers, we conducted five focus groups in two geographic locations (North Carolina and Massachusetts). Each focus group consisted of between 6 and 8 participants, with a total of 36 focus group participants. We recruited participants with the assistance of about 30 CAM practitioners and integrative care clinics, all of which were identified as experienced providers by knowledgeable informants. These providers included practitioners of a wide range of CAM services representing the five types of CAM services defined by the National Center for Complementary and Alternative Medicine (NCCAM); these include whole medical systems, energy therapies, manipulative and body based therapies, mind-body therapies, and biologically based therapies. Providers who agreed to help with recruitment were asked to post flyers and fact sheets about the study in their offices. These materials included a toll-free number for interested persons to call to determine whether they qualified for the study.

Individuals were eligible for this study if they were 21 years of age or older; received treatments by one or more complementary or alternative therapy practitioners for a health problem in the last year; found their treatments to be beneficial; and felt comfortable and willing to discuss their experiences in a group. We assigned eligible individuals to groups in each location to obtain as much variation as possible in age, gender, and the type of CAM therapies used.

Prior to beginning each focus group discussion, participants signed consent forms and completed a short questionnaire covering variables related to sociodemographic characteristics, general health status, and service utilization. Once these forms were completed, an experienced moderator conducted the focus groups, while a co-moderator took notes. To aid in the analysis and to capture the words of participants, each focus group session was digitally recorded. Each focus group discussion lasted approximately 2 hours. Participants received a $\$ 40$ honorarium to cover their time and any incidental expenses.

We transcribed the digital recordings, entered the transcriptions into QSR NVivo [18], a qualitative data analysis software program, and used the categories from the focus 
group interview guide to code the data. We then generated reports based on these codes.

Together with moderator and co-moderator summaries that were prepared after each group, two research analysts conducted an independent review of the reports and used qualitative content analysis [19] to identify common themes and outcomes reported by the focus group participants. We inductively coded the responses for common themes and then placed them into broader conceptual categories that reflected the CAM outcome domains suggested by Verhoef and colleagues [4]. We also examined the data to identify any additional domains that may have emerged and that were not included in the whole systems outcome model. Finally, we identified participant quotations to illustrate the outcomes that emerged during the analysis.

Table 1. Characteristics of Focus Group Participants

\begin{tabular}{|c|c|c|}
\hline Characteristic & Number & Percent \\
\hline \multicolumn{3}{|l|}{ Age } \\
\hline $25-34$ & 5 & 13.9 \\
\hline $35-44$ & 7 & 19.4 \\
\hline $45-54$ & 9 & 25.0 \\
\hline $55-64$ & 10 & 27.8 \\
\hline 65 or older & 5 & 13.9 \\
\hline \multicolumn{3}{|l|}{ Gender } \\
\hline Female & 30 & 83.3 \\
\hline \multicolumn{3}{|l|}{ Health status } \\
\hline Excellent & 3 & 8.3 \\
\hline Very good & 13 & 36.1 \\
\hline Good & 15 & 41.7 \\
\hline Fair/poor & 5 & 13.9 \\
\hline \multicolumn{3}{|l|}{ Race } \\
\hline White & 33 & 91.7 \\
\hline \multicolumn{3}{|l|}{ Education } \\
\hline High school graduate or GED & 1 & 2.8 \\
\hline Some college or technical school & 4 & 11.1 \\
\hline College graduate & 10 & 27.8 \\
\hline Post graduate or professional degree & 21 & 58.3 \\
\hline \multicolumn{3}{|l|}{ Marital status } \\
\hline Married & 26 & 72.2 \\
\hline Divorced & 6 & 16.7 \\
\hline Never married & 4 & 11.1 \\
\hline \multicolumn{3}{|l|}{ Income } \\
\hline$\$ 45,000$ or less & 12 & 36.4 \\
\hline$\$ 45,000-\$ 70,000$ & 8 & 24.2 \\
\hline$\$ 70,001$ or greater & 13 & 39.4 \\
\hline
\end{tabular}

\section{RESULTS}

The characteristics of participants are shown in Table $\mathbf{1 .}$ Among the 36 participants across the 5 focus groups, the majority $(n=33)$ described their race as white/Caucasian. The majority of participants were female $(\mathrm{n}=30)$ and married $(n=26)$; more than half $(n=21)$ were under 55 years old. Overall, participants in the focus groups were well educated with more than half $(\mathrm{n}=21)$ having a postgraduate education or professional degrees. The participants' annual incomes varied: of those who provided this information, 12 had incomes of $\$ 45,000$ or less, 8 had incomes of $\$ 45,000$ $\$ 70,000$, and 13 reported annual incomes greater than $\$ 70,000$.

\section{General Health Status and CAM Utilization Background}

Overall, a majority $(n=31)$ of the participants considered themselves to be in good, very good, or excellent health. Even so, they reported having a wide variety of health problems, including hypertension, gastrointestinal problems, vision problems, and arthritis and other pain-related issues for which they first visited a CAM practitioner. Others mentioned seeking CAM for general wellness or interest in learning self-regulation and self-help techniques. Table $\mathbf{2}$ provides a list of specific health problems prompting first time usage of CAM practitioners.

Table 2. Reasons for First Visit to a CAM Provider

\begin{tabular}{|l|c|}
\hline \multicolumn{1}{|c|}{ Reason } & Number \\
\hline \hline Depression, anxiety, stress, post-traumatic stress disorder & 11 \\
\hline Arthritis and joint stiffness & 6 \\
\hline $\begin{array}{l}\text { Miscellaneous health problems not diagnosed or resolved } \\
\text { by conventional practitioners }\end{array}$ & 3 \\
\hline Knee pain, injuries, replacement & 3 \\
\hline $\begin{array}{l}\text { Gynecological problems (menstrual, infertility or pelvic } \\
\text { problems) }\end{array}$ & 3 \\
\hline General aches and pains & 2 \\
\hline Headaches & 2 \\
\hline $\begin{array}{l}\text { Head injuries (depressed skull fracture or post-concussive } \\
\text { syndrome) }\end{array}$ & 2 \\
\hline Vision problems & 1 \\
\hline Stomach or gastrointestinal problems & 1 \\
\hline Sinus problem & 1 \\
\hline Prostate infection/prostatitis & 1 \\
\hline Chronic cough & 1 \\
\hline Bladder control & 1 \\
\hline High blood pressure & 1 \\
\hline Smoking & 1 \\
\hline Gait issues & 1 \\
\hline Post-surgical recovery & 1 \\
\hline
\end{tabular}


Participants in these groups were experienced CAM users. Most $(n=26)$ reported that their first visit to a CAM provider occurred over 2 years before the study and reported that they had used multiple types of CAM therapy. About half of the participants $(n=17)$ had used between 4 and 6 different therapies, and one reported trying 21 total therapies over many years. Acupuncture $(n=24)$ was the most common therapy ever used by participants, followed by chiropractic $(n=14)$, Reiki $(n=13)$, yoga $(n=12)$, and craniosacral and massage therapies $(n=11$ each). Table 3 is a full list of the CAM therapies used by these participants.

Table 3. Complementary and Alternative Medicine Therapies Used by Participants

\begin{tabular}{|l|c|}
\hline \multicolumn{1}{|c|}{ CAM Therapy } & Number \\
\hline \hline Acupuncture & 24 \\
\hline Chiropractic & 14 \\
\hline Reiki & 13 \\
\hline Yoga & 12 \\
\hline Craniosacral therapy & 11 \\
\hline Massage therapy & 11 \\
\hline Tai Chi & 8 \\
\hline Energy healing & 6 \\
\hline Homeopathy & 6 \\
\hline Herbs and supplements & 5 \\
\hline Feldenkrais Method & 3 \\
\hline Ton Ren & 3 \\
\hline Alexander Technique & 2 \\
\hline Cranioelectrical stimulation & 1 \\
\hline Naturopathy & 1 \\
\hline
\end{tabular}

Almost all $(n=35)$ reported having medical insurance; however, only 12 participants indicated that their insurance covered CAM services. Of these, only 1 indicated that insurance covers all of the types of CAM used. Close to half $(n=14)$ of the participants reported spending over $\$ 1,000$ out of pocket to see CAM practitioners in the year prior to the study.

\section{Physical Health}

We asked participants to discuss the type of physical problems that caused them to seek treatment from a CAM provider. While the type of physical conditions mentioned varied, participants often mentioned that they had sought help from CAM providers for problems or conditions when conventional medical treatments had been unsuccessful. The problems were similar to those reported in the demographic survey (see Table 2). A majority said that they used CAM for pain-related problems such as back pain, arthritis, dental pain while waiting for dental treatment, residual pain from a car accident, migraines, or other chronic headaches. These included acute, recurrent, and chronic pain. Many also said they saw a CAM practitioner for medical conditions such as upper respiratory infections, reflux, hypertension, side effects of conventional cancer treatments, tendonitis, or autoimmune conditions like Sjögren's syndrome. Some sought treatment to improve restricted function resulting from musculoskeletal or neurological conditions such as Parkinson's disease, vertigo, or the effects of a stroke. Table $\mathbf{4}$ provides examples of participants' comments by the type of provider and physical condition for which they saw these providers.

When asked what type of benefit they received from the therapies used, several said that they received some type of improvement in their condition, such as decreased pain, decreased markers of inflammation, increased flexibility, increased energy, better sleep, and increased mobility. CAM helped one participant "to be able to walk from one place to another and not feel a constant pain. That is what it has helped me. I feel physically stronger and I can do more." Another remarked that "I started seeing him [acupuncturist] and I got more energy, but also he really helped me with my very severe menstrual cramps. My period got much more comfortable, lighter and such. It is much, much easier now. Even though I came in for a specific thing [lack of motivation] his idea was that he wanted to treat me and not a symptom."

Although some participants agreed that the degree of symptom relief received from CAM therapies depends on the symptom being treated, almost all reported receiving some type of relief from the symptoms for which they visited a CAM practitioner. Some received temporary relief of their symptoms as a result of CAM use, which was sometimes referred to as "short-term relief." One focus group member commented that "I keep going back because my back is always cranky I would say and the middle of my back hurts and my shoulders hurt. I can exist without it [craniosacral therapy] but I know that I can go and get relief." Another explained that "every time he [chiropractor] does an adjustment it gets the bones in my back in line. I don't hurt until they go out of place again in two hours to two days. It seems like now, almost three years later, that it [relief] is getting a little longer and for that I am grateful." A few indicated that CAM helped to avert surgery, and some attributed their expedited recovery to CAM use. As one participant described, "I did have a herniated disc in my lower back and the Alexander technique [practitioner] taught me how to move, how to stand and so forth so I wouldn't reinjure myself continuously as it healed."

When asked about whether any of their conditions had been resolved by CAM use, most agreed that a physical health condition or problem was cured or resolved through CAM treatment. Patients described the benefits that the received from CAM in various ways:

I had acid reflux and I was on medication for ten years for that and through this diet program I was on we figured out what was going on and I haven't taken medication for that in over a year now. I haven't had any episodes. When I see her it is for different things she doesn't treat me for that any more and I get lasting results [when I see her]. 
Table 4. Participants' Comments on Type of Physical Problems and CAM Treatment Sought

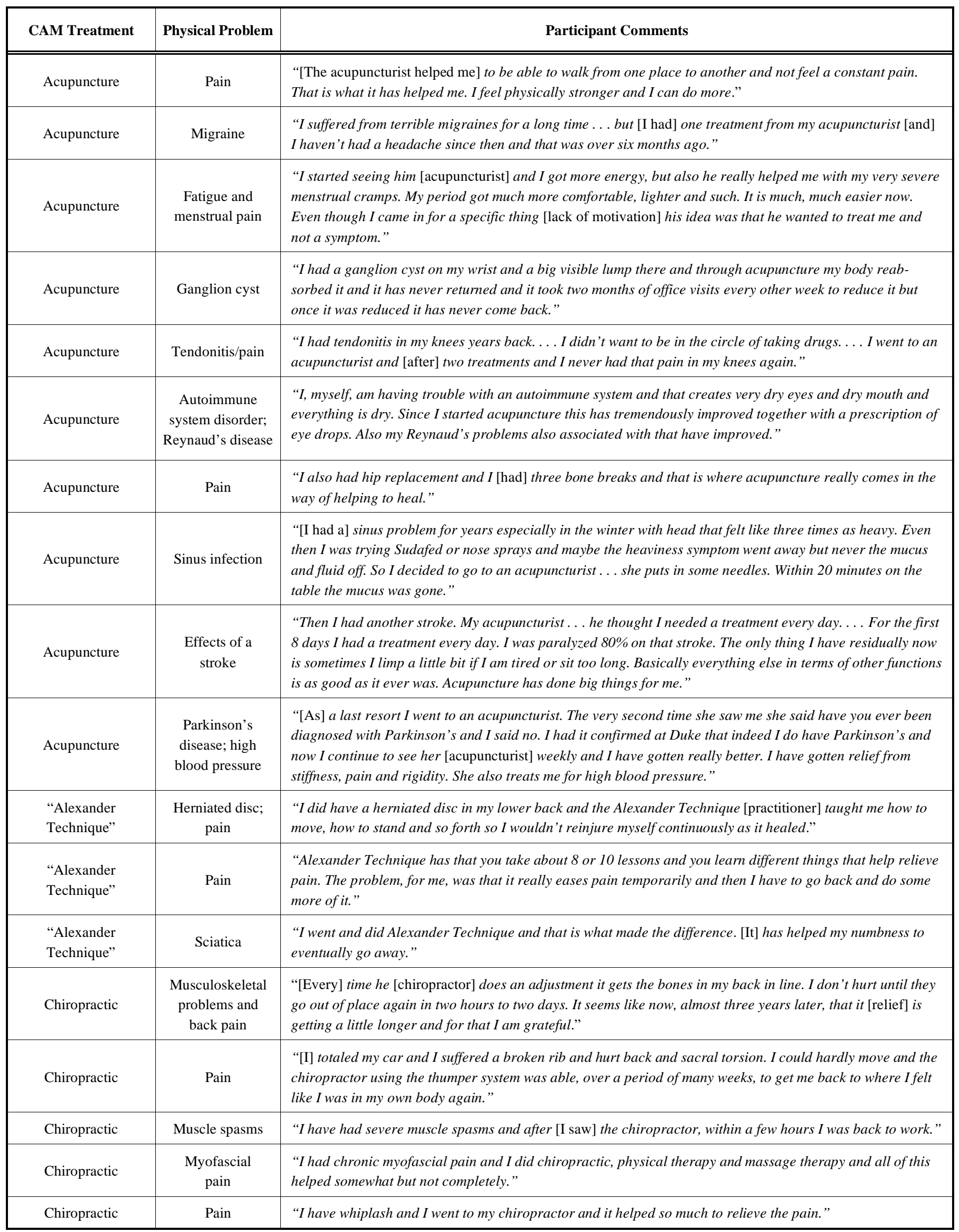


(Table 4) contd....

\begin{tabular}{|c|c|c|}
\hline CAM Treatment & Physical Problem & Participant Comments \\
\hline Craniosacral therapy & Pain & $\begin{array}{l}\text { "I keep going back because my back is always cranky I would say and the middle of my back hurts and my } \\
\text { shoulders hurt. I can exist without it [craniosacral therapy] but I know that I can go and get relief." }\end{array}$ \\
\hline Craniosacral therapy & $\begin{array}{l}\text { Headache and other } \\
\text { pain related symp- } \\
\text { toms }\end{array}$ & $\begin{array}{l}\text { "I went to see this craniosacral practitioner because I had headaches, my back and shoulders hurt and I had } \\
\text { a really tight and painful stomach. ... [The] treatment [provided] an immediate relief but [it was] also like a } \\
\text { compounded thing. Right after each treatment I feel, and still feel, totally amazing." }\end{array}$ \\
\hline Craniosacral therapy & Spinal stenosis & $\begin{array}{l}\text { "Though the therapy hasn't and it won't cure the spinal stenosis, it has helped. I, too, used to have a lot of } \\
\text { pain but now it [is painful] only when I think about it. The cranio therapy is helping and it has just made me } \\
\text { calmer." }\end{array}$ \\
\hline Massage therapy & Pain & $\begin{array}{l}\text { "I started with a massage therapist and he started doing energy work which cured the pain from my torn } \\
\text { muscles." }\end{array}$ \\
\hline $\begin{array}{l}\text { Massage therapy and } \\
\text { yoga }\end{array}$ & $\begin{array}{l}\text { Back and shoulder } \\
\text { pain }\end{array}$ & $\begin{array}{l}\text { "I used the massage therapy and yoga . . I had back pain in my upper shoulder. So for that I have a friend of } \\
\text { mine who is a massage therapist... I started going to her because she said that she could help me. She also } \\
\text { suggested going to yoga and stuff and it helped the pain go away." }\end{array}$ \\
\hline $\begin{array}{l}\text { Multiple therapies not } \\
\text { specified }\end{array}$ & Acid reflux & $\begin{array}{l}\text { "I had acid reflux and I was on medication for ten years for that and through this diet program I was on we } \\
\text { figured out what was going on and I haven't taken medication for that in over a year now. I haven't had any } \\
\text { episodes. When I see her it is for different things she doesn't treat me for that anymore and I get lasting re- } \\
\text { sults [when I see her]." }\end{array}$ \\
\hline Reiki & $\begin{array}{l}\text { Cancer and effects } \\
\text { of chemotherapy }\end{array}$ & $\begin{array}{l}\text { "[I tried }] \text { a number of things like Reiki which I have no idea how it works . . it put me in a frame of mind so I } \\
\text { could heal. It was definitely a part of my healing process but it didn't cure the cancer." }\end{array}$ \\
\hline Tai Chi and yoga & Arthritis pain & $\begin{array}{l}\text { "I have both arthritis and an inflammatory illness . . it affects your shoulders and your hips. My range of } \\
\text { motion was almost nothing. I couldn't comb my hair and could barely stand up. I started doing my Tai Chi } \\
\text { and yoga... I realized that when I did do it, then [the pain] felt better for a few hours after." }\end{array}$ \\
\hline Tai Chi and yoga & Knee pain & $\begin{array}{l}\text { "I had unbelievable pain in my knee and then as I began to come to my own senses I did go to my doctor who } \\
\text { sent me to a rheumatologist and I and still take Naprosyn for this pain. But I turned also to massage and that } \\
\text { did help and in the fall I began taking Tai Chi and I last year added Polarity yoga." }\end{array}$ \\
\hline $\begin{array}{l}\text { Self care: homeo- } \\
\text { pathic remedy }\end{array}$ & Vertigo & $\begin{array}{l}\text { "Another one was vertigo...one morning I woke up with it and I called this doctor. . . He [my husband] got } \\
\text { three little medicines [from the doctor] with directions take them every } 15 \text { minutes or so. Within four hours I } \\
\text { was on my feet and it was over." }\end{array}$ \\
\hline $\begin{array}{l}\text { Self care: homeo- } \\
\text { pathic remedy and } \\
\text { Ton Ren }\end{array}$ & Dental pain & $\begin{array}{l}\text { "I had tooth troubles this past year, before I could get to see my dentist I was in quite a bit of pain. So instead } \\
\text { of getting a prescription for a pain killer I used homeopath Miasm which I was able to look up because of my } \\
\text { own system. Then when the Miasm stopped working I switched to Ton Ren . . and I was able to knock out the } \\
\text { pain for about probably four hours." }\end{array}$ \\
\hline
\end{tabular}

I suffered from terrible migraines for a long time ... but [I had] one treatment from my acupuncturist [and] I haven't had a headache since then and that was over six months ago.

I went to see this craniosacral practitioner because I had headaches, my back and shoulders hurt and I had a really tight and painful stomach. . . the treatment [provided] an immediate relief but [it was] also like a compounded thing. Right after each treatment I feel, and still feel, totally amazing.

Interestingly, across all the groups, participants felt that even when they were not totally cured by their CAM therapy, the out-of-pocket costs were worthwhile. As one participant put it,

I know alternative therapies can be expensive but you get healed or learn how to deal with whatever it is on your own and you are not continually saying I need a new prescription. Even if you need to be reevaluated it is not something that is going to cost you [a lot], even if you have to pay for the visit to your naturopath or your massage therapist, they give you the tools to heal yourself.

\section{Psychological and Emotional Health}

While most of the group discussions focused on physical health benefits, many participants also shared how CAM therapies positively affected their psychological and emotional well-being. Several participants noted that they were dealing with issues of depression, stress, anxiety, or other emotional problems. As with the physical health problems, participants reported seeing a range of CAM providers to help them cope with these conditions or from whom they received psychological benefits as a result of the CAM therapy, regardless of the presenting problem.

These benefits included a decrease in symptoms of depression, anxiety, and stress. Almost all participants reported that CAM treatments had a positive effect on their emotional 
well-being. They also reported being generally able to function more effectively as a result of CAM use. One participant explained that "when I have seen my acupuncturist I feel stronger and more alert. I feel like I have less stress and I am a much more calm, centered person and I think that is one of the reasons I don't get sick." Another perceived that CAM treatment had caused an overall improvement in wellbeing: "I think this [CAM therapy] has helped me hugely decrease stress and generally feel better." The general sentiment of the participants is summarized in the words of one of the group member, who stated that "I find I feel a combination of energy and I am much less anxious [as a result of the CAM therapy]. I worry much less the rest of the day and my mood is much better. I feel happier and more willing to do things." Participants also discussed the connection between how they felt psychologically and their ability to improve physically. As one said, "I don't think we can stress enough how the CAM doctor and all the practitioners realize that your mental state is what allows the body to heal."

Many group members also spoke about receiving positive psychological benefits such as increased resilience, happiness, and hopefulness. One participant commented that " $I$ feel more resilient over my outlook overall. I feel like I am much better able to deal with whatever arises for me and just really feel like a more balanced, sane person." Another averred that "it [CAM therapy] has changed my person $110 \%$. Before I was in it I was an angry northerner and close minded and hating life. I found alternative therapies and I am balanced, centered and happy." Moreover, a few participants commented that the CAM therapy provided a way to regain a sense of control over their lives, with one expressing that "I was looking for support during chemo and it really helped me a lot then in that I can definitely say it helped my whole sense of well being and [helped me] gain a sense of taking control especially during that watch and wait time."

For some, these psychological benefits resulted from the resolution of long-standing physical problems and had an impact on their families as well as themselves:

It has affected the household as well. I am not as negative and my daughter said "Mom all you talked about was the pain and the worry and whatever went along with it." She said I don't talk about it anymore and my husband said he knew I was getting well when he started getting into trouble. I am not concentrating on my health problem and I am able to garden and babysit the neighbor kids and do lots of things that I had no energy or interest in two years ago.

Only a few people spoke about the degree of symptom relief relative to the psychological benefits of CAM use. Those who did agreed that the CAM practitioner either helped them to recognize a stressor or gave them tools and techniques, such as deep breathing and yoga, to deal with stress or to maintain a positive mental state.

\section{Social Health}

Social health is another outcome domain that participants spoke about in some detail. Many talked about how the CAM practitioner becomes a caring member of their social network, one who "knows about your family, asks about your kids" and "sends personal greetings on holidays." The two components of social health that participants spoke most about were beneficial relationships with practitioners and increased access to other resources-in other words, a therapeutic relationship and care coordination.

Therapeutic Relationship. Despite the fact that most participants stressed that they believed the positive results they had experienced from CAM therapies are a function of the specific techniques used, they also spoke about the relationship they have with the practitioners as a benefit of CAM use. Their comments indicate that participants believe these relationships enhance their physical and psychological health outcomes. Almost all participants who talked about this relationship agreed that their CAM provider spends time listening to them and talking to them to get to know them as people. As one participant articulated, "I certainly look forward to my visits to her so we can talk because I am not currently in talk therapy but talking with her satisfies that need. She knows me and I am free to express my feelings around her." That same sentiment is conveyed by another participant: "[My therapist] said we will talk about it [my symptoms] again next week and every week she starts out by finding out how my week went, how I felt from the treatment I had gotten the week before and just my general well being." While several participants were quick to point out that doctors provide this same approach if they have time or that not all CAM practitioners relate to their clients in this way, many valued the personal interest and caring shown by CAM practitioners.

Whereas a few participants conveyed that they were partners in their care with their doctors, some participants expressed that their relationship with their CAM practitioners was a partnership that offered a form of support not typically found with conventional medical providers. As one participant put it,

For the most part the alternative therapists gives [sic] you more time, gives you love, gives you validation, and I think it is an exchange of energy and [in] a whole different way we are in sort of a partnership with the therapist as opposed as to the "I am the doctor" and I am in charge and you do what I say to do.

Participants in one of the groups talked more specifically about what CAM practitioners do that helps to improve their mental state. They felt that their practitioners built trust, took time to hear what they were saying about their symptoms, created an atmosphere in which participants did not feel alone, and provided validation that the problem or condition was real. In the words of one participant, "Because somebody [the practitioner] was there with me touching me, being reassuring my anxiety level from like a 10 went to down to like $a 2$ and I would definitely attribute that to two things the Reiki itself which is relaxing but also to her caring presence."

Care Coordination. Participants valued care coordination that was provided by their CAM practitioners. A few spoke about having a provider who served as a resource in selecting conventional medical providers as well as other CAM providers. Some of these participants were patients of integrative medical practices (i.e., practices that use both primary care doctors and CAM providers); others were patients of doctors who had also been trained in specific CAM thera- 
pies such as homeopathy. Some had switched to primary care doctors who were CAM practitioners or worked collaboratively with CAM practitioners to have the best of both worlds with regards to health care. One of these participants explained that "My family practitioner is an MD and holistic doctor and he has a whole list of people like acupuncturist [s] and chiropractors and he recommends midwives when you are in his care." Another described their CAM practitioner as a care coordinator: "My practitioner is a wonderful resource for other things like if you need a good orthopedist or good dentist or she recommended an acupuncturist."

In other cases, participants reported that their CAM providers recognize when clients need to see a medical provider and direct them to seek further conventional medical care or second opinions. One person spoke specifically about how an acupuncturist recommended that it might be best to see a neurologist; the neurologist diagnosed the problem as Parkinson's disease. The words of another person convey how some participants experienced at least some degree of care coordination by CAM practitioner:

I had an ankle that would flare up and swell and it got increasingly worse and more frequent and they [the doctor] thought I had gout and [the acupuncturist] said "you go to that rheumatologist and find out and let me know. I don't think it is gout." It was not gout but it was a compensation for the way I walk because of the condition that I have. Orthotics and acupuncture have helped.

A few described that sometimes there is communication but not coordination between their conventional medical providers and CAM practitioners. In one instance, a participant discussed how her CAM therapies appeared to be reducing her dependence on oral diabetes medications. Her medical provider and CAM therapists agreed to discuss her case. In this case, the focus group participant indicated that the medications were less expensive than the CAM therapy, so the CAM therapy was discontinued.

Although many had the opinion that their CAM providers did not coordinate their care with conventional medical providers, a few indicated that they wished there was more of that type of coordination, and a small number discussed how their medical providers supported and encouraged their use of CAM, even though they did not coordinate with the CAM therapists. One participant illustrated this by describing how "he [the rheumatologist] said I should continue it [CAM use] until such time that it is not benefiting me any more and then come back to him. He said the only thing he could do was prescribe the medication."

\section{Spiritual Health}

Participants also spoke about changes in their philosophy of healing and spiritual health as additional benefits of CAM use. For many of them, spirituality appeared to be related to a sense of hope, trust, or a connection to a higher power that might hasten healing processes. Several also expressed that they gained a sense of empowerment and a feeling of being in control as another benefit. Many talked about this sense of empowerment in terms of being able to overcome feelings of helplessness to take charge and do something to help improve their conditions.
Even though they expressed a belief that personal determination is important in the healing process, many also expressed that CAM practitioners often provided a needed sense of hope that their conditions or situations would improve and that the CAM providers had caring attitudes toward their clients' overall care. The sentiments of these participants were conveyed by one who said that "hope is one of the biggest things that they encourage in you and gives you a sense of hope no matter what the outcome is in terms of physical terms. Maybe they give you the hope to be healed or maybe it is not going to happen but then there is the hope of [a] less painful or less traumatic time." Another expressed that

The treater [CAM practitioner] gives you some hope and you find that sometimes there is an immediate response and it doesn't last very long but at least it is out there and there is a possibility [of improvement]. I think there is a mystery there. In some way [it's] spiritual and you use the word mind and body here. I think we have a lot of that in the whole [CAM] business.

A few participants spoke about how their CAM practitioners believed in the power of the universe and the power of nature and the effect that that belief had on the way they viewed their own health conditions or problems. The underlying theme of this type of power can be summarized by a participant for whom

It [CAM] slowed me down long enough to think about it and it made me realize, I must be here in this exact situation for some reason. I may never get the answer to why I have diabetes when I have none of the risk factors but I am here. I am treating it and there are options for me and, for me, it has really been important I have learned to accept that I am here where I am at this point because of some kind of plan.

Throughout all of the discussions, participants conveyed that they felt a sense of empowerment as a result of CAM therapy. Several individuals talked about recognizing their own inner strength, feeling they have some amount of control over their health outcomes, being empowered to take charge of their conditions, and believing in their own abilities to cope with their conditions as a result of their relationships with and the encouragement they received from their CAM providers:

They give resources and they plan with you and they make you feel like you are not just being told to take this pill three times a day and call me in a week if you are not feeling better or if you try this and you can't do it and you are not willing to do it then you are never going to get better.

So it was definitely like the empowerment factor that like there was homework to do in between sessions that you could do to help yourself. That is part of what I like about complementary approaches too, a lot of them, not all of them, you're in charge and taking care of yourself.

There is a whole system of balancing and this has given me a sense of empowerment. It has alleviated a lot of fears for the future because of being crippled or being in a wheelchair or worse.

For some, CAM use brought about more than the specific effects of treatment and served to catalyze changes in their philosophy of healing: 
It isn't so much for me a symptom and treatment as much as it has been a very different way of life and looking at my body and my health and having alternative methods to support that. To think not about so much the cause and affect [sic] symptoms but to think more about my overall wellness. It is more about bringing the whole system into balance and that is a real...not so much causeleffect these symptoms. Anyway this idea of coming back into balance and shifting my thinking about my body and what wellness is and what balance is. That, in itself I think, is very healing.

\section{Impact on Health-related Behaviors}

In each group, people also talked about a benefit of CAM not specifically mentioned in the four outcome domains of the Verhoef [4] model; they discussed the positive effects that using CAM therapies had on their health-related behaviors. Participants spoke about focusing on their overall health more closely and being motivated to take better care of themselves as a result of their CAM use. Several individuals also discussed the lifestyle changes they had made to help prevent more serious illnesses; these changes included stopping smoking, decreasing alcohol consumption, increasing exercise, and changing their diets.

Many said they improved their poor eating habits because CAM use helped them to make better food choices or to pay closer attention to their diet. This theme is illustrated in the following comment by a group member: "I don't know if this directly came from the yoga people or Tai Chi but the more I do it the more I feel better about myself and the more I choose to eat a better diet and stay away from the sugar and the meats and fats." Several participants also stated that they had begun exercising more as a result of their CAM experience. For example, one participant commented that, as a result of her yoga and Tai Chi classes, "I am now taking the classes at home and doing aerobic exercise which I didn't do for health before." A few individuals said that they had stopped smoking and had reduced their alcohol intake as a result of receiving complementary and alternative therapy.

Most of those who experienced health-related benefits felt that they were supported in these lifestyle changes by their CAM providers through receiving CAM treatments, learning self-help techniques from the therapist, or being monitored and encouraged by their CAM practitioners. One participant claimed that "because of the [CAM] therapy I have been able to get into healthy habits . . . I had gained a lot of weight after taking some antidepressant medications and I have been able to get my weight back [down by] about 15 pounds and it is not directly related but I think it is the self confidence to do better and take more control of my diet." Another commented that acupuncture treatments "helped to reduce sugar cravings." A few also viewed their CAM providers as role models whose healthy behaviors they wanted to emulate: "In yoga class when I can only get my hand on my knee and they have theirs on the floor I look at them as a role model and say wow look at the level of flexibility or control they have. It is kind of nice to have them leading the class and being proficient at it and you can say I can do that and achieve that." Another said, "Yeah both the Tai Chi teachers are vegetarians and they are long and lean. You respect that and that is a role model." Others stated that their CAM practitioners used techniques to eliminate crav- ings or provided other support: "The allopathic physician says quit smoking or drink less, lose weight . . but my acupuncturist or my massage therapist will support me through it." Another example is found in this comment: "I quit smoking cigarettes and I attribute that to my massage therapist and he is the one who does Reiki."

The general theme expressed by those who felt that CAM therapy impacted their health was reflected by the comment that "it seems that when you feel good you want to do things that feel good. I think you are [also] more aware of things that don't feel good [as a result of CAM use]." This statement suggests that CAM users experience increased body awareness as well as heightened motivation for health behavior change. A more in-depth analysis of the role of CAM providers in health behavior change is explored in a separate study.

\section{DISCUSSION}

This study provides insight into the experience of satisfied CAM users who derive a range of benefits from CAM therapies. Consistent with the preliminary model of outcome domains suggested by Verhoef and colleagues [4], we found that most benefits described by the focus group participants were captured by the physical, psychological, social health, and spiritual outcomes included within this whole systems framework. The physical benefits include resolution or improvement in presenting problems and nonspecific benefits such as improved sleep, energy, mood, and concentration or focus. The reported psychological benefits include both relief from mental health problems, such as depression and anxiety, and positive psychological benefits, such as resilience, hope, and empowerment. Participants also reported social health benefits (i.e., increased social networks and social capital as CAM providers become a source of support and caring), and providers connected CAM users to a range of resources. Many of these CAM users felt enriched by their exposure to a different view of health and well-being and, in some cases, a sense of spirituality.

An additional outcome domain that emerged from the responses was the impact of CAM on health behaviors. Several focus group participants mentioned how they had made lifestyle changes as a result of their experience with CAM, noting that such changes may have resulted from feeling better because of the treatments themselves and/or because of the encouragement and support they received from the CAM practitioners. Embedded within these accounts of improved diets and physical activity levels is the notion that such changes were concomitant with psychological changes in control perceptions, self esteem, and confidence. From a whole systems perspective, the intertwining of these different benefit domains is expected because the outcome domains are viewed as being synergistically linked to each other. Our analysis of the possible outcome domains of CAM use underscores this synergy because many of the representative quotations for one domain encompass elements that can be classified within other domains. Given this inter-

\footnotetext{
In a separate study we examined the possible mechanisms involved in the health behaviour change facilitated by CAM treatment. The paper reporting these findings is currently under review.

Williams-Piehota P, Sirois FM, Bann C, Isenberg K, Walsh EG. Agents of change: What role do CAM providers play in health behavior change? Soc Sci Med (submitted)
} 
connectedness, our findings highlight the importance of including a behavioral domain as one of the key areas of improvement that may result from CAM treatment.

The model of CAM outcomes proposed by Verhoef and colleagues [4] also considers the role of contextual factors such as the importance of the patient-practitioner relationship in CAM treatment. According to Long [2], the CAM practitioner is a potential source of influence that can have a direct effect on treatment outcomes through the quality of the relationship with the patient. Although we did not specifically analyze the focus group responses for the role of patient-practitioner factors, their presence is clearly reflected in the CAM users' narratives. In addition to receiving social health benefits, such as social support and advocacy, CAM users reported experiencing other benefits that arose from the therapeutic relationship with their practitioners. These included patient-centered care, emotional support and encouragement, care coordination or referrals to other useful resources.

In addition to the patient-practitioner relationship, there was some evidence for the other sources of CAM outcomes suggested by Long [2]. Several participants mention how specific CAM techniques facilitated their healing processes and led to both improvements in their symptoms and their knowledge of how to continue to care for themselves. Similarly, some participants specifically made reference to the different perspective on health and healing that evolved through their experiences with CAM, and how this holistic philosophy changed how they viewed themselves and their lifestyle. The findings of this qualitative analysis should be considered within the context of several limitations. Despite our efforts to recruit a diverse group of CAM users, the groups were primarily white, female, and well educated. While we reached out to a broad array of CAM providers to assist in recruiting subjects and did succeed in recruiting individuals who had experience with a wide range of CAM therapies, the sample of CAM users recruited was far from being all inclusive. In particular, we are missing traditional therapies used by ethnically diverse populations. Finally, we purposely recruited individuals who felt that they had benefited from CAM to keep with our objective of identifying domains of benefit derived from CAM use. We might have obtained different responses and insights had we simply recruited individuals who use or had used CAM therapies and heard about all aspects of their experiences.

Despite these limitations, it has been suggested that qualitative analysis is appropriate for extending rather than testing theories [20]. Accordingly, the proposed extension of the outcome domains to include behavioral outcomes that is suggested by our findings is more important than the generalizability of our findings, which remain to be verified.

\section{CONCLUSIONS}

These findings provide insight and direction for CAM outcomes measure development and for identifying existing scales appropriate for use in CAM outcomes research. Based on these findings, we developed and piloted measures for some of these domains, reported elsewhere [21]. These include measures of the patient-provider relationship, which may be used as quality measures or as predictors of healing. ${ }^{2}$ In addition, several concepts emerged in the focus groups that may warrant further investigation. These included increasing body awareness (i.e., the ability to notice and modify one's physical and behavioral response to stress). Further, participants described experiencing relaxation as a result of CAM therapy and, in some cases, learning to become more relaxed on their own. Some participants reported an expansion in their social network that went beyond their relationships with the CAM practitioners or receipt of care coordination. These CAM clients appeared to have a sense of group membership or a new identity associated with their CAM use. How this occurs and what role it plays in the lives of CAM users or in outcomes of treatments are other possible areas of investigation.

\section{CONFLICT OF INTEREST}

This study was supported by an independent research grant provided by RTI International. The authors have no conflicts of interest with the study.

\section{ACKNOWLEDGMENTS}

The authors would like to acknowledge the contributions of Karen Isenberg, MS, who conducted some of the focus groups and the CAM providers who helped recruit focus group participants by distributing flyers and other recruitment materials. This study was supported by an independent research grant provided by RTI International.

\section{REFERENCES}

[1] Long AF, Mercer G, Hughes K. Developing a tool to measure holistic practice: a missing dimension in outcomes measurement within complementary therapy. Complement Ther Med 2000; 8: 26-31.

[2] Long AF. Outcome measurement in complementary and alternative medicine: unpicking the effects. J Altern Complement Med 2002; 8: 777-86

[3] Verhoef MJ, Lewith G, Ritenbaugh C, et al. Complementary and alternative medicine whole systems research: beyond identification of inadequacies of the RCT. Complement Ther Med 2005; 13: 20612.

[4] Verhoef MJ, Vanderheyden LC, Dryden T, Mallory D, Ware MA. Evaluating complementary and alternative medicine interventions: in search of appropriate patient-centered outcome measures. BMC Complement Altern Med 2006; 6: 38.

[5] Verhoef MJ, Vanderheyden LC, Fonnebo V. A whole systems research approach to cancer care: why do we need it and how do we get started? Integr Cancer Ther 2006; 5: 287-92.

[6] Ritenbaugh C. Guiding concepts for whole systems research. Whole systems research in cancer care-report of meeting in Troms $\emptyset$ (Sommaroy), 14-16 September 2005. Complement Ther Med 2006; 14: 157-64.

[7] Boon H, Brown JB, Gavin A, Westlake K. Men with prostate cancer: making decisions about complementary/alternative medicine. Med Decis Making 2003; 23: 471-9.

[8] Gollschewskia S, Kitto S, Andersona D, Lyons-Wall P. Women's perceptions and beliefs about the use of complementary and alternative medicines during menopause. Complement Ther Med 2007; 16: 163-8.

[9] Kroesen K, Baldwin CM, Brooks AJ, Bell IR. U.S. military veterans' perceptions of the conventional medical care system and their

\footnotetext{
${ }^{2}$ In a separate analysis we found support for the role of the patient-provider relationship in CAM outcomes, as measured by a newly developed measure of provider support. A paper reporting these findings is currently in preparation for possible publication.

Walsh EG, Bann C, Sirois FM, Greene AM. Symptom relief in CAM: The role of patient-provider relations and empowerment. In preparation.
} 
use of complementary and alternative medicine. Fam Pract 2002; 19: 57-64.

[10] Rao JK, Arick R, Mihaliak K, Weinberger M. Using focus groups to understand arthritis patients' perceptions about unconventional therapy. Arthritis Care Res 1998; 11: 253-60.

[11] White MA, Verhoef MJ, Davison BJ, Gunn H, Cooke K. Seeking mind, body and spirit healing - why some men with prostate cancer choose CAM (Complementary and Alternative Medicine) over conventional cancer treatments. Integr Med Insight 2008; 3: 1-11.

[12] McCaffrey AM, Pugh GF, O'Connor BB. Understanding patient preference for integrative medical care: results from patient focus groups. J Gen Intern Med 2007; 22: 1500-5

[13] So DW. Acupuncture outcomes, expectations, patient-provider relationship, and the placebo effect: implications for health promotion. Am J Public Health 2002; 92: 1662-7.

[14] Paterson C, Britten N. Acupuncture for people with chronic illness: combining qualitative and quantitative outcome assessment. J Altern Complement Med 2003; 9: 671-81.

[15] Paterson C. Measuring changes in self-concept: a qualitative evaluation of outcome questionnaires in people having acupuncture for their chronic health problems. BMC Complement Altern Med 2006; 6: 7.

[16] Luff D, Thomas KJ. "Getting somewhere," feeling cared for: patients' perspectives on complementary therapies in the NHS. Complement Ther Med 2000; 8: 253-9.

[17] Krueger R. Focus groups: a practical guide for applied research. $2^{\text {nd }}$ ed. Sage: London 1994.

[18] QSR International Pty Ltd. NVivo qualitative data analysis program. 7 ed. QSR International Pty Ltd: Melbourne, Australia 2002.

[19] Pope C, Ziebland S, Mays N. Qualitative research in health care: analysing qualitative data. BMJ 2000; 320: 114-6.

[20] Vanderheyden LC, Verhoef MJ, Hilsden RJ. Qualitative research in inflammatory bowel disease: dispelling the myths of an unknown entity. Dig Liv Dis 2006; 38: 60-3.

[21] Bann CB, Walsh EG, Sirois FM, Kline T. Measuring provider support in complementary and alternative medicine. $5^{\text {th }}$ Annual IN-CAM Symposium, Toronto, ON 2008.

(C) Greene et al.; Licensee Bentham Open.

This is an open access article licensed under the terms of the Creative Commons Attribution Non-Commercial License (http://creativecommons.org/licenses/ by-nc/3.0/) which permits unrestricted, non-commercial use, distribution and reproduction in any medium, provided the work is properly cited. 